University of Nebraska - Lincoln

DigitalCommons@University of Nebraska - Lincoln

May 1997

\title{
Institutional, Evolutionary, and Demographic Contexts of Gender Roles: A Case Study of !Kung Bushmen
}

\author{
Patricia Draper \\ University of Nebraska - Lincoln, pdraper1@unl.edu
}

Follow this and additional works at: https://digitalcommons.unl.edu/anthropologyfacpub

Part of the Anthropology Commons

Draper, Patricia, "Institutional, Evolutionary, and Demographic Contexts of Gender Roles: A Case Study of !Kung Bushmen" (1997). Anthropology Faculty Publications. 4.

https://digitalcommons.unl.edu/anthropologyfacpub/4

This Article is brought to you for free and open access by the Anthropology, Department of at DigitalCommons@University of Nebraska - Lincoln. It has been accepted for inclusion in Anthropology Faculty Publications by an authorized administrator of DigitalCommons@University of Nebraska - Lincoln. 


\title{
16 Institutional, Evolutionary, and Demographic Contexts of Gender Roles: A Case Study of !Kung Bushmen
}

\author{
Patricia Draper
}

\section{In a Foraging Camp, 1968}

$\mathrm{Sa} / /$ gai is a 10 -year-old foraging girl. It is 9:00 A.M. The sun is already hot; even the sand is already uncomfortably warm under her bare feet. She scoots back into the partial shade of a nearby bush. She looks across the camp, her quick glance taking in the 10 grass huts that are the residences of the several families, some with young children, that form the hunting and-gathering band she and her family live with. She looks about for something to do. Her mother and infant brother have already left for the day with some of the other women from the camp; some of the other women are also carrying nursing children. They will be gone for the day gathering bush foods. She sees her father a few feet away. He sits in the shade of a storage platform near her parents' hut and is sharpening his arrows, preparing for the next day's hunt. Several children of the camp play near him. When they come within an arm's reach, he shoos them away. The poison on the arrows is lethal; he wants them at a safe distance.

$\mathrm{Sa} /$ /gai's glance comes to rest on an old couple, //Oka and /=Oma, her grandparents, sitting together at their own fire outside their grass hut. Two other adults, also members of the band, sit with them. She wanders over and sits cross-legged between her grandparents. /=Oma, her grandfather, is pulling the hot mongongo nuts out of the hot ash where he has been roasting them. As they cool, his wife,
//Oka, cracks them expertly between two stones. Wordlessly, Sa//gai reaches out her opened palm to her grandmother. The old woman drops several warm nut meats into $\mathrm{Sa} /$ /gai's palm and resumes cracking. Still chewing the nuts, Sa//gai stands and moves off to a clearing at the edge of the camp. Here some of the older children are playing a throwing game. She joins in without changing the pace of the game.

\section{In a Settled Village, 1988}

$/ / \mathrm{N}$ is a $\mathbf{5 0}$-year-old !Kung woman. She and her husband, $\mathrm{N} / / \mathrm{au}$, live in a settled village about 10 kilometers from !Angwa, the regional administrative center of about 100 people. It is 8:00 A.M. This morning she stands outside her mud hut, thinking about how there is too much to do. Her husband, N//au, has already milked the few cows they have that are giving milk. He left the milk, in two brimming pails, with her for churning. Then, with the help of $/ / \mathrm{N}$ 's grown son, and two nephews, $\mathrm{N} /$ / au drove the cattle and goats to the well. $\mathrm{N} /$ / au will be away most of the day at!Angwa, seeing the local headman about a business matter.

$/ / \mathrm{N}$ calls her grown daughter, $\mathrm{N}$ !ai, to take the pails of milk and prepare them for churning. This is a task that N!ai usually performs, often with the help of $\mathrm{Di} / / \mathrm{au}, / / \mathrm{N}$ 's own mother. $\mathrm{Di} /$ / au has been widowed for years and, since widowhood, has lived with her 
daughter and son-in-law. Di//au, though old, is an important help to her daughter's village in making the homestead run.

N!ai appears in answer to her mother's call. She straps her 3-year-old to her back as she approaches. / $\mathrm{N}$ looks at her daughter with a mixture of pride and dissatisfaction. N!ai is strong and beautiful. She finished 6 years of schooling in !Angwa and can speak and write in SeTswana, the language of the country. This is an unusual accomplishment for a !Kung of any age. N!ai is a good daughter and willing to work. Yet N!ai did not marry her child's father. Her lover, a !Kung man her own age, had a good job in a distant town and did not want to marry her. N!ai's first child was "a child of the bush," as the !Kung say. Now her belly is swelling again; this time the baby is by a Tswana (non-!Kung) man. "Well," //N thinks, "At least she is here, helping us to live."

$/ / \mathrm{N}$ calls out to three men of her village who are saddling donkeys for a trip to !Angwa. She wants them to carry sour milk with them to give to her son, her youngest child, a boy of 13 years. He attends school at!Angwa and boards with a Bantu family during the week. On weekends, he comes back to his parents' village to help with the work.

Knowing that the morning milk is being churned and that other milk is going to her boy at school, $/ / \mathrm{N}$ sets off for the garden. She picks up a bucket on her way out of the village so she can bring water from the well on her return trip. Yesterday she saw a break in the garden fence. It must be repaired before the goats get in and ruin the crops.

\section{!Kung ETHNOGRAPHY}

These scenes describe observations in !Kung villages made 20 years apart at the beginning of my research among !Kung San in 1968 and, more recently, in 1987-1988. In the past 20 years, I have made several trips to the western Kalahari in Botswana where !Kung (also known as Zhun/wasi of !Kung San) live. Over this time, I have observed marked cultural changes as the people have moved from a tradition of hunting and gathering to living as full time, settled food producers. The !Kung are one of several indigenous southern African groups known, collectively, as Khoisan. They contrast with the predominant Bantu-speaking populations of southern Africa in being smaller in stature, lighter in skin color, having cultural traditions of foraging rather than pastoralism, and having distinctive non-Bantu languages characterized by click phonemes. In recent decades, the !Kung have had increased contact with cattle-keeping peoples (such as the Tswana and Herero) who have been moving into regions of the Kalahari that were previously occupied primarily by !Kung.

The !Kung economic transformation has come about gradually over several decades. This process had begun well before I started my studies. However, in the late 1960s when my research began, I was able to work with two populations, one living as hunter-gatherers, another as settled, food producers and clients to Bantu patrons. In the late 1980 s, the !Kung of western Botswana were all settled and deriving the bulk of their subsistence from stock raising, gardening, and government-distributed surplus foods. The people obtained some foods from the bush but only on a sporadic basis.

In this chapter I have two objectives. One is to detail the consequences of changes in social structure for gender roles and to show how economic change affects the lives of males and females. The second objective is to explain how my perspective on the relationship between behavior and social structure has changed over time. More particularly, I have been influenced by ideas in evolutionary biology. Although I still see human beings as embedded in a cultural context, I also see that other insights come by viewing humans as another mammalian and primate species. These ideas will be elaborated more fully in a later section of the paper.

My early research focused on the ways in which social and economic practices affect the 
socialization of children for gender roles, the relations between women and men, and the organization of family relationships. As will be detailed below, child and adult gender roles are affected by social and economic practices. However, the description of correlation does not speak to causation. Why did the !Kung who lived by food-producing adopt more sex-segregated and gender-asymmetric customs? Why was the interaction between the sexes among the foragers more egalitarian? A brief ethnographic account of foraging and settled !Kung is provided below.

The lifestyle of foraging !Kung has been well described in numerous monographs and papers (Lee 1969, 1979; Lee and DeVore 1976; Marshall 1976; Howell 1979; Solway and Lee 1990; Yellen 1990). The foragers lived in small, kinship-based, mobile bands, moving many times during the year in pursuit of game or vegetables. The environmental limitations were severe for the hunter-gatherers. Standing water, outside of the rainy season, was available at a few hand-dug wells. Most times of the year, group size was limited to 30 to 40 people, because a larger population exhausted available plant and animal foods, even with frequent moves during the year.

Twenty years ago, some !Kung were still living primarily by hunting and gathering. They alternated bush life with occasional visits to other !Kung who lived at cattle posts as clients and hangers-on of cattle-keeping groups, chiefly of the Tswana or Herero tribes. The contrasts between the foragers and the settled people as they lived in the 1960 s will be described below. By the late 1980s, the !Kung of western Botswana all were settled around permanent water and attempting to make a living by a mixture of stock-raising, gardening, work for Bantu, government dole, and occasional foraging. The contemporary !Kung will be described in a later section of the paper.

The lifestyles of the !Kung who, even 20 years ago, were settled, have been less well described. The settled !Kung lived more or less permanently near year-round water sources. They subsisted by foraging, hunting, and gar- dening, and through ties of clientship to Bantu cattle keepers (Wiessner 1982; Wilmsen 1982, 1988; Lee 1984; Biesele et al. 1989). Living conditions were not as severe for settled !Kung as they were for the foragers. Settled people were spared the frequent moves and having to live away from water for several weeks at a time. It was common for young !Kung men to work as cattle herders for Bantu cattle owners; many !Kung families lived on the fringes of Bantu villages as clients and sometimes servants of the pastoralists. While their lifestyle was impoverished in comparison with their Bantu patrons, many !Kung were attracted by the prospect of regular food and the opportunity to learn the economic techniques of the wealthier cattle people (Draper 1975b, 1991).

\section{Child Behaviors}

My chief interest was to understand how child behavior varied according to whether the children lived in foraging groups or in sedentary groups. At that time, a number of scholars, influenced originally by the culture and personality school, were devising more systematic ways to explore the processes whereby culture was transmitted via the socialization process to children. These researchers focused on empirical studies of overt behavior (in place of the more elusive concept of "personality") and on social institutions and physical environment (in place of the more global concept of "culture"). Works by Barry et al. (1959), Whiting and Whiting (1975), Whiting (1965), Ember (1973), Whiting and Edwards (1973), Wiesner and Gallimore (1977), and Morelli (chap. 15) are examples of this approach.

Over a period of about 18 months, during different seasons and different times of the day, I collected a series of randomized, timed, behavior observations on about 75 children, divided about equally between the two groups. More-detailed descriptions of the methods employed can be found in published articles (Draper 1973, 1975a, 1976, 1978; Draper and Cashdan 1988). I also was concerned with adult work roles, for I knew that adult activi- 
ties would shape the lives of children. I collected daily work-activity diaries on men and women of the foraging groups, as well as weekly censuses and diagrams of the many band encampments.

The behavior of the foraging children shows little sex differentiation. The most obvious explanation for the similarities in girls and boys is that children are not trained to do economically useful tasks and, as a result, escape early pressure for sex-differentiated behavior. In many societies, particularly agricultural or pastoral ones in which much adult time is spent in subsistence work, children are pressed into service at early ages to help adults with their work (Barry et al. 1957). Girls typically are assigned more tasks than boys, and at earlier ages than boys, because their mothers want help and reason that the girls will be learning genderappropriate tasks. Boys spend more of their early years free of pressure for responsibility and obedience. Adult men and older boys eventually train them in their work roles, but training begins at later ages for boys than for girls.

!Kung children of the foraging groups do virtually no useful work until very late ages, well over 12 years. This is an unusually permissive regimen for children in comparison with the expectations for child labor in many other traditional societies where data on children's work have been collected (Whiting and Whiting 1975). The foraging children are freed from work because of the nature of the work their parents do and because of the environment in which they live. Men and women in their hunting and gathering rounds can walk long distances in search of food, and they realize that children cannot keep up. Children become tired, slow the work party down, and may need to be carried, thus reducing the efficiency of one or more adults. Furthermore, for about 7 months of the year, there is no rainfall in the Kalahari. Much of the terrain in which the adults forage is dry and hot. If children accompany the workers, extra water will have to be brought for them, also increasing the work load of the adults.
The solution !Kung parents have devised is to leave children behind at the main camp. Other adults can be counted on to be there to supervise children. In this society, most adults actively hunt or gather only every other day, or less frequently. Both girls and boys have equal amounts of leisure during the day. Even child care does not seem to fall heavily on the girls. Mothers look after most of the needs of infants and toddlers themselves, not using children on a regular basis as mother's helpers.

Sedentary children, however, show more sex differences, mirroring the greater sex differentiation in the roles and behaviors of the adults. Sedentary children also do more economically useful tasks, a fact explained by the more numerous responsibilities of their parents and the beginning attempts by parents to put their children to work. Girls stay closer to home base and helped their mothers; boys are more frequently out of the home village, often doing chores associated with domestic stock. From early ages, boys range freely with other boys, have more contact with Bantu and, relative to girls, have a head start in learning non-!Kung languages (Whiting and Whiting 1973).

On the other hand, even in the foraging groups, the behavior profiles of girls and boys are not identical. In fact, they differ along many of the same lines that female and male juveniles differ in nonhuman primate species (Hiraiwa-Hasegawa chap. 6). Girls are physically less active, more likely to be in physical contact with others. They are spatially less farranging, more likely to receive interruption and redirection by adults (Draper 1975a; Draper and Cashdan 1988). Girls are more likely to spend time with adults where their behavior is closely supervised. Boys more often play with peers and are less likely to be close to adults and adult supervision. Even though the requirements of daily living among the foragers do not facilitate gender-segregated treatment of children, it appears that girls and boys gravitate to different microenvironments. I could see that "choices" made by girls early in life could be implicated in a common pattern of sex differentiation in which girls receive, at 
earlier ages, stronger pressures for compliance and obedience. Staying closer to adults, particularly women, they have less time to explore on their own and in the company of peers.

\section{Adult Bebaviors}

Adult behaviors in the foraging and sedentary groups also differ. Men and women of the foraging groups are egalitarian in their dealings with each other. They are typically found in mixed-sex groups in the camp settings, although their work is usually done in same-sex groups. Women do not show deference to men. Living in small bands without well-developed leadership roles, they arrive at decisions by a consensus in which women participate along with men. Women as well as men are involved in primary production. Women retain control over the foods they gather and to whom it is distributed. Women as well as men leave the camp during a day's work. As a result, both men and women are well acquainted with the terrain through which the group moves over months and years.

Sedentary !Kung, on the other hand, show clearer gender segregation. Certain tasks are more strongly identified with one sex or the other. Men and women do not mix as easily and informally in everyday settings, and women avoid and defer to men in many situations (Draper 1975b, 1991).

These characterizations of gender relations among !Kung in the two settings are based on many observations of the interactive styles between men and women and the amount and types of work done by both sexes. Social structural features also promote gender egalitarianism. Many customs among the foragers make it difficult for men to coerce women by virtue of their superior strength (Draper 1975b). For example, the prevailing bilateral residence arrangements insure that women among the foragers are rarely, if ever, in the position of living away from their own kin. As a result, a woman cannot be isolated by her husband and mistreated by him, nor can young women be easily intimidated by their husbands' kin because their own relatives are typically close by. The close proximity of individual households in the foraging bands and the people's custom of spending nearly all of their waking and sleeping time out-of-doors in full view of other villagers mean that women benefit from the informal protection of public surveillance, which acts as a deterrent to most acts of male aggression.

Among the sedentary !Kung, many features of the social ecology (which among the foraging !Kung seem to have guaranteed a kind of informal gender egalitarianism) are being dismantled. With greater property accumulation comes greater male control over property, particularly the more prestigious forms of property such as livestock and cash. The work of women is increasingly domestic and confined to the village locale. Perhaps even more important to male ascendancy in the settled camps are men's interactions with the Bantu pastoralists who were neighbors of the settled !Kung. !Kung men act as intermediaries for women and children vis-à-vis the Bantu. Not surprisingly, it is the men who have mastered the Bantu languages and not the women. Sedentary women, relative to foraging women, have lost ground to men. They have become confined and relegated to a back seat in many public settings. Men have moved to the forefront, acquiring cash, language, and livestock. But why? What is there in accumulating material property and adopting a more complex economy that accelerates and intensifies gender asymmetry?

My thinking about the relations between women and men parallels my thinking about the sex differences in the behavior of girls and boys. The behaviors changed concomitantly with contextual change, but any statements I make about these correlations is not an explanation. Cultural practices among the sedentary !Kung account for substantial gender segregation, whereas a different set of socioecological factors among the foraging !Kung account for a relative absence of gender-segregated behaviors. Yet, the behavioral profiles of the girls and boys in the foraging groups are not the same, despite the absence of cultural pressure for gender differences. There is another reality be- 
neath performance and context that shapes the behaviors of girls and boys.

I continued to think that the socioecological approach had value; culture and economy play a major role in structuring gender relations. But, culture, institutions, and economy do not tell the whole story. I began to think harder about what it is about the particular form of society among the nomadic !Kung that promotes gender egalitarianism and how that acts as a constraint on the more familiar pattern of gender asymmetry that appeared to "lurk beneath the surface" of social interactions and social institutions.

At this stage in my thinking and writing (mid-1970s) I was concerned with several issues. In the !Kung case, property accumulation and economic change were associated with gender segregation and increasing female subordination. But why should things work this way? Furthermore, why should the more "primitive" economic conditions of the foraging !Kung promote gender equality? There are other descriptions of hunter-gatherer groups in which sex-role symmetry is well established (Hart and Piling 1960; Rose 1960), so the mere fact of a hunter-gatherer subsistence base does not guarantee equality between the sexes. Socioecological factors enter into the structuring of gender relations, but social structure and cultural ideology do not provide good theoretical reasons for why gender asymmetry develops in the first place. It takes the sociobiological perspective to fit additional pieces of the puzzle, as will be discussed below.

\section{SOCIOBIOLOGY}

In the 1970s I began to read the developing sociobiological literature (DeVore 1965; Trivers 1972; Dawkins 1975; Williams 1975; Wilson 1975; Alexander et al. 1979; Dickemann 1979; Zihlman 1981; Lancaster 1985). My graduate training in anthropology had stressed the "natural history" approach to the study of "man." However, I began to think more seriously about what it means to be mammal and primate, as well as "human." I did not abandon a commitment to empirical measures of human behavior, grounded in an understanding of social structure and ecology, but I began to recognize that humans are like other organisms with the same problems to solve, such as staying alive, mating, and parenting.

Reading the sociobiological literature made me appreciate fully the fact that men and women, like the sexes in other mammalian species, have important reproductive asymmetries. In nonsocial species in which males play no parental role in provisioning the mother or in defending the young, the reproductive specialization of the sexes and the dimorphism in size do not have necessary implications for the ability of one sex to coerce the other. In other species that live in multimale or heterosexual groups, male-female relations assume the familiar male superior/female inferior hierarchy as a consequence of males competing among themselves for access to females. On the other hand, in mammalian species in which the parental role is critical to the survival of young, male and female interests more nearly coincide in the welfare of their young. In such species, it is usual to see some forms of mate guarding on the part of both male and female members of the pair. Either mate can be disadvantaged if the other deserts the pair for another mate. The displays of jealousy are often more intense in the male than in the female. This is explained on the grounds that the male member of a monogamous pair can be cuckolded (tricked into rearing the young sired by another male), whereas the female cannot, under natural circumstances, be tricked into bearing offspring that are not genetically her own.

Humans carry the mammalian specialization to an extreme by producing only a few offspring who mature slowly and who require large amounts of parental care in order to survive. Women are committed to a disproportionate amount of this parental work since, unlike males, they cannot recoup one or a few infant or child deaths by finding another mate (Lancaster 1985). A woman who loses a child has lost not only that individual with whom she 
has personal ties, but she has lost irreplaceable reproductive time. A man who loses even all his children may experience an acute sense of personal loss, but he can replace them by establishing one or more additional mating relationships with other women. The reproductive inequality between the sexes gives rise, of course, both to the behavioral and somatic dimorphisms between the sexes and to the differing reproductive potentials of the sexes.

Following this line of reasoning, one sees the human female is encumbered to an extent not seen in other species. Because of the extremely dependent state in which young are born and because of their slow development, any roles that conflict with a woman's reproductive roles are generally avoided by her as an individual or denied her by other interested parties, especially her kin and her mates. The human mother must continue to invest high levels of parental care in several young simultaneously. Unlike other primate females who greatly reduce care of the next oldest offspring (by no longer nursing or carrying the subadult juvenile) when a new infant is born, a woman maintains not one but several dependent offspring, albeit at different stages of dependence (Lancaster 1985). With each new child, she adds to her encumberment and goes farther and farther into "debt" in the sense that her dependents multiply, but her physical reservoir of energies remains the same. In order to rear offspring, a woman must have help. Some aid comes from her kin, but nearly all human groups attempt to regulate access to the reproductive capabilities of women by designating a mate (husband) and making him and his kin share in the work of rearing or defending the children.

Humans live in groups that include numerous other individuals who are eligible as mates. As a result, the sexual contract (paternity certainty in exchange for protection and economic resources) has consequences for other male-female relationships besides marital ones. Daughters and sisters of men, for example, have a vested interest in maintaining alliances with their male consanguines, not only because they benefit from men's labor but because these men protect them from other men. A woman's mate, if she has children by him, is also more likely to benefit her and her children than are foreign, unrelated men.

It is probably true to say that in the past environments of evolutionary adaptation in which human social, psychological, and sexual behavior have been molded by natural selection, a woman has had few degrees of freedom. A woman who mistakenly judges her economic or social resources risks the survival of her offspring, who, in technologically "simple" societies, are wholly dependent on her nurturing, especially during the first few years of life. This fundamental and rather dismal picture (from the point of view of modern individualistic and humanitarian values) needs to be kept in mind when thinking about behavioral and institutional inequalities. I do not suggest that women are without choices or strategies, nor that they have been selected for passivity. I do argue that women relative to men must be extremely cautious in their economic and reproductive careers because, unlike men, they have only limited ability to recoup their losses.

As a cultural anthropologist, I have found that an extremely interesting aspect of cultural variability is the extent to which the underlying reproductive asymmetry of men and women is institutionalized. Any circumstance in which fertility is low and monogamy is imposed, either as a result of ecological constraints or social conventions, is a good place to look for restraints on the ability of males to coerce females. The reason is that, in this situation, the reproductive interests of the sexes are the same (Alexander et al. 1979; Alexander 1987) or more nearly identical than in other human groups. Under the ecological conditions in which some contemporary hunter-gatherers, such as the !Kung, have lived, the requirements for male labor are sufficiently high that most men can only support one mate and her children at a time (Hewlett 1988). In technologically more advanced societies that have sur- 
pluses in the form of stored grains or herds of domestic animals, the fitness interests of the sexes are not the same. Men can advance their own fitness at the expense of other men by competing for access to more than one mate. Where resources are potentially abundant and can be disproportionately controlled by a single man or alliances of men, male-male competition has direct consequences for male fitness (Dickemann 1979; van den Berghe 1979). In such social systems, the variance in male reproductive success is high, and men have much to gain by winning in competitive engagements with other men and, thereby, gaining access to women.

The sociobiological perspective provides another piece of the puzzle about sex, gender asymmetry, and culture. The substantial gender equality that is seen among the foraging !Kung must be related to the ecologically imposed low ceiling on male-male competition. In the hunting-and-gathering setting, the best a given man can do, reproductively speaking, is the best a woman can do. Not surprisingly, monogamy is the prevailing marriage form; polygyny is allowed but rarely practiced. Because of the "simple" technology, the requirements of mobility, the inability to store surpluses, and the unpredictable nature of both vegetable and animal resources, men and women must work equally hard to maintain themselves and their dependents (Lee 1968). Ecological uncertainty makes sharing, especially the sharing of animal protein, a necessity, and a consequence of the sharing is minimized male-male competition.

By settling at permanent water and beginning to adopt the food-producing practices of the Bantu, !Kung raise the ceiling on malemale competition. In the late $1960 \mathrm{~s}$, the shift to sedentism was not far advanced, for the major incursion of Bantu (primarily of the Herero tribe) took place in the late 1950s. Few !Kung in these early years owned stock. A few men managed small herds on a contract basis for Bantu owners, but most of the settled !Kung were clients or hangers-on to the Bantu, whose numbers were increasing steadily. The men who worked for the Bantu had definite advantages. Their families drank milk and received occasional payments of meat and agricultural produce. In comparison with men living in the nomadic groups, they had few obligations to share their food.

There also were disadvantages to settling with Bantu. !Kung complained that their compensation for work was not sufficient and, in truth, the !Kung servants lived in much poorer circumstances than their Bantu patrons. The main complaint of !Kung who worked for Bantu in the 1960s (as well as now) was that they were not paid well enough to get ahead, to become independent stock owners in their own right.

Another disadvantage to !Kung men working for Bantu is that some Bantu men wanted to take !Kung women as wives. More often, rather than marrying them, Bantu men enter into informal liaisons with!Kung women, not marrying them, but fathering children by them and not contributing to their support. This put !Kung men in the unenviable position of having fewer !Kung women to marry themselves and seeing their daughters begin reproductive careers without husbands who could help their wives and in-laws. Most men who become servants or clients to the Bantu manage to find !Kung wives, but not a few of them rear at least one child born to their wives by a Bantu lover.

In the context of the competition from Bantu men over access to women of their group, it is not too surprising to find changes in the structure of gender roles among the sedentary !Kung in the 1960s. If !Kung men have moved into more prominent "brokering" roles vis-à-vis Bantu, and if they encourage their women to remain in the background, these moves are understandable as strategies to reduce the sexual competition with men of a wealthier group. If !Kung women "cooperate" by reducing their spatial mobility and by minimizing their contact with the pastoralists (especially the men of these groups), this also is understandable if they want to maintain their 
claims on support and protection from men of their own groups. !Kung women can be expected to avoid contact with non-!Kung men as long as men of their own groups are willing and able to assist them.

In this discussion I hope to have made clear the different perspectives on behavior that can be gained by adopting, on the one hand, a social structural perspective, and on the other, a sociobiological perspective. The two models are in no way antithetical; in fact, they provide complementary kinds of insight. The changes in subsistence practices from a life based on foraging and economic egalitarianism to a life based on a settled, food-producing economy and increased potential for economic differentiation, led to a multitude of changes in !Kung social practices. Some of these changes are visible in the mundane organization of adult work roles and the socialization of children. Other changes are visible in the realm of sexual, reproductive, and gender relations between men and women.

\section{New Directions, New Data, AND OLD INTERESTS}

In 1987-88 I spent 15 months in the Kalahari studying aspects of aging and life-cycle development among the !Kung. ${ }^{1}$ As part of the study, I collected demographic data, the core of which came from reproductive interviews with about 330 adults ranging in age from 18 years to more than 75 years. These data speak directly to matters of sex, reproduction, and gender differences, although, in this context, the questions are not about gender asymmetry and sexual egalitarianism but about sex differences in reproductive strategy.

In brief, the acculturative changes that were already apparent in the late 1960s have continued. All !Kung in western Botswana are now settled, and the Bantu presence has increased. !Kung now subsist on their stock (mostly goats with a few cattle), sporadic hunting and gathering, and a periodic government dole of corn meal and beans. Some !Kung men work as cat- tle herders for Bantu families. A recent 7-year drought has made gardening nonproductive. Many !Kung customs remain in place: village residence remains largely bilateral, and marriages are almost entirely monogamous. The biggest change is in the timing of marriage and in the frequency of out-mating by !Kung women with non-!Kung men. In traditional !Kung practice, women are married in their early teens. This custom was continued by !Kung in the 1950s and 1960s, both among those settled and those living in the bush. Today women marry at later ages. Most significantly, a rising number of women do not marry, or if they do, marry after having had one or more children out of wedlock, often by non-!Kung men.

What this trend will mean in the long run for gender relations is not clear. In the short run, it seems advantageous to women. In the old days !Kung girls were married young and to men an average of 5 to 10 years older than they (Howell 1979). As girls, they had little power to refuse the matches arranged by their parents. Though many of these early marriages ultimately failed, it was often after a long period of unhappiness and resentfulness on the part of the young brides. The reasons for these early marriages were economic. Parents wanted their daughters to marry in order to secure their welfare and so that the family of the bride could gain access to the hunting skills of the groom. In former times, the hunting prowess of men was highly esteemed by people living in the bush as well as by the settled !Kung. By all accounts, the game was more abundant formerly, before fences disrupted the movements of the game herds and before the introduction of domestic stock and mounted hunting.

Today, many !Kung women do not marry until their middle or late teens. Others do not marry at all but establish informal liaisons with men by whom they have children. These unions often do not lead to marriage; instead, the girl stays at home with her own parents and kin. Her lover visits her in her village but does not have rights in her as a husband.

At least two aspects of cultural change facilitate the rise in multigenerational extended 
families and female-headed households. First, middle-aged men and women (and in some cases the elderly parents of middle-aged people) have sufficient wealth to keep their daughters at home whether or not they have husbands. Sedentary people work harder than do foragers, and there are many tasks to be completed. The grown daughters are welcome as working members of the villages as are the children they bear. Second, young !Kung men in the modern acculturated setting have less to offer young women (and the parents of young women) in comparison with what they could offer as hunters when people lived as foragers. As mentioned above, game is scarce, largely because of the increased numbers of cattle. Alcohol is now available in the areas of !Kung settlement, and the frequent drinking and resulting knife fights involving !Kung men do not enhance their reputations or prestige. It appears that, at present, husbands and sons-in-law are less important than they once were. The labor that men provide is still needed, and the social positions that men occupy as heads of families are still important. However, under the new economy, one man, as head of an extended family compound, can provide reasonably well for his wife and children. Women still need such men, but it appears that they do not need them as husbands. If they have fathers, brothers, sons, or uncles to provide an umbrella of protection, it is apparently sufficient.

Some data I collected in recent field work with !Kung show some of the effects of cultural change on the reproductive differences among different cohorts of men. These data come from reproductive, employment, and acculturation interviews collected from about 110 men over the age of 20 years. Analysis of these data shows the effects of cultural change on the completed fertility of men of different age cohorts. Older men (over about 60 years of age) had about 3.5 children and a small variance. These older men began their reproductive careers well before the arrival of the Bantu in large numbers. Younger men, roughly 45 to 62 years of age had a higher average number of children (about 4.0) and a greater variance.
Men of this age group spent the bulk of their reproductive years during a time of increased exposure to Bantu influence and presence. Inspection of the individual cases who make up the middle cohort shows that men who had high reproductive success differed from those with low reproductive success in having longterm residential association with Bantu and more years of employment with the cattle owners (Kranichfeld and Draper 1990; Kranichfeld (1991).

A comparison of the reproductive success of men and women of different ages makes a similar point (Draper and Buchanan 1992). These data are based on reproductive interviews with about $\mathbf{3 3 0}$ adults, ranging in age from 18 to over 80 years. The total numbers of children (3.6) born to old people (60 years and over) are equal for the two sexes, whereas for a younger age cohort, (45-59 years of age), the sexes do not have the same fertility. !Kung women of this 45-59 year cohort average about 4.6 children. Men of the same age group have produced an average of about 3.5 children. The discrepancy may be explained by the common pattern whereby men marry younger women and continue fathering children at later ages than women. In this case, the age-hypergynous factor does not account for the difference.

Figure 16.1 "Children of Mixed Ethnicity as a Percentage of All Live Births" shows the percentage of mixed-ethnicity children born to women of the age groups 18-29, 30-44, 45$59,60+$. As can be seen, older women produced few children by mating with Bantu men. Younger cohorts of women have produced a steadily increasing percentage of children fathered by non-!Kung men. The men of younger cohorts, the bulk of whose adult lives have been spent during the period of maximum acculturative pressure from Bantu, are losing out to Bantu in reproductive competition for !Kung women.

Another surprising piece of this newly emerging pattern in family organization and reproductive strategy is the finding that the survivorship of the children of "mixed matings" is 


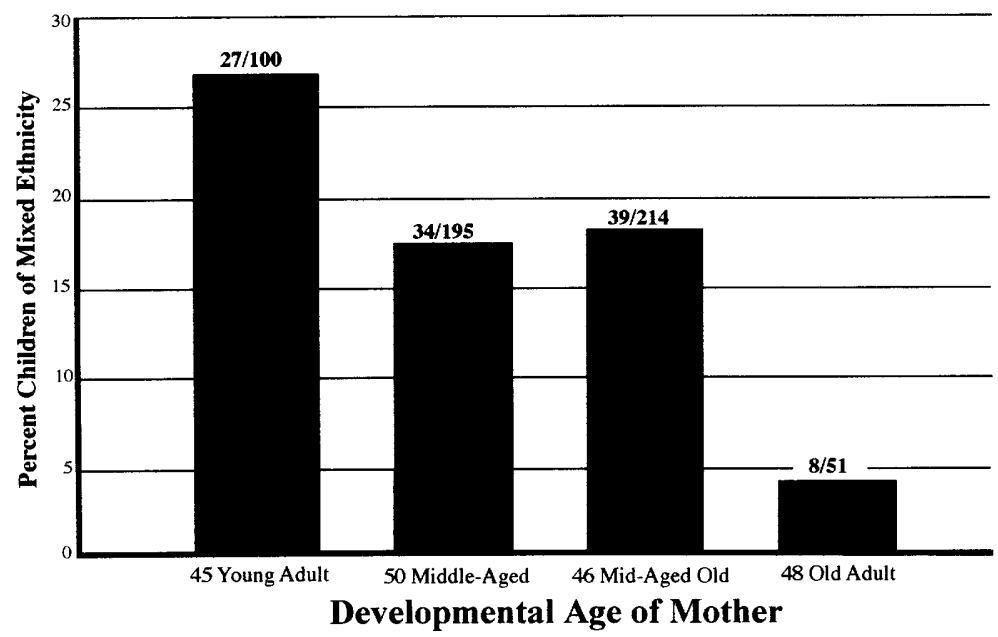

FIGURE 16.1. Children of mixed ethnicity as a percentage of all live births; percentage of children of mixed ethnicity born to women of the age groups 18-29 years, 30-44 years, $45-59$ years, and over 60 years.

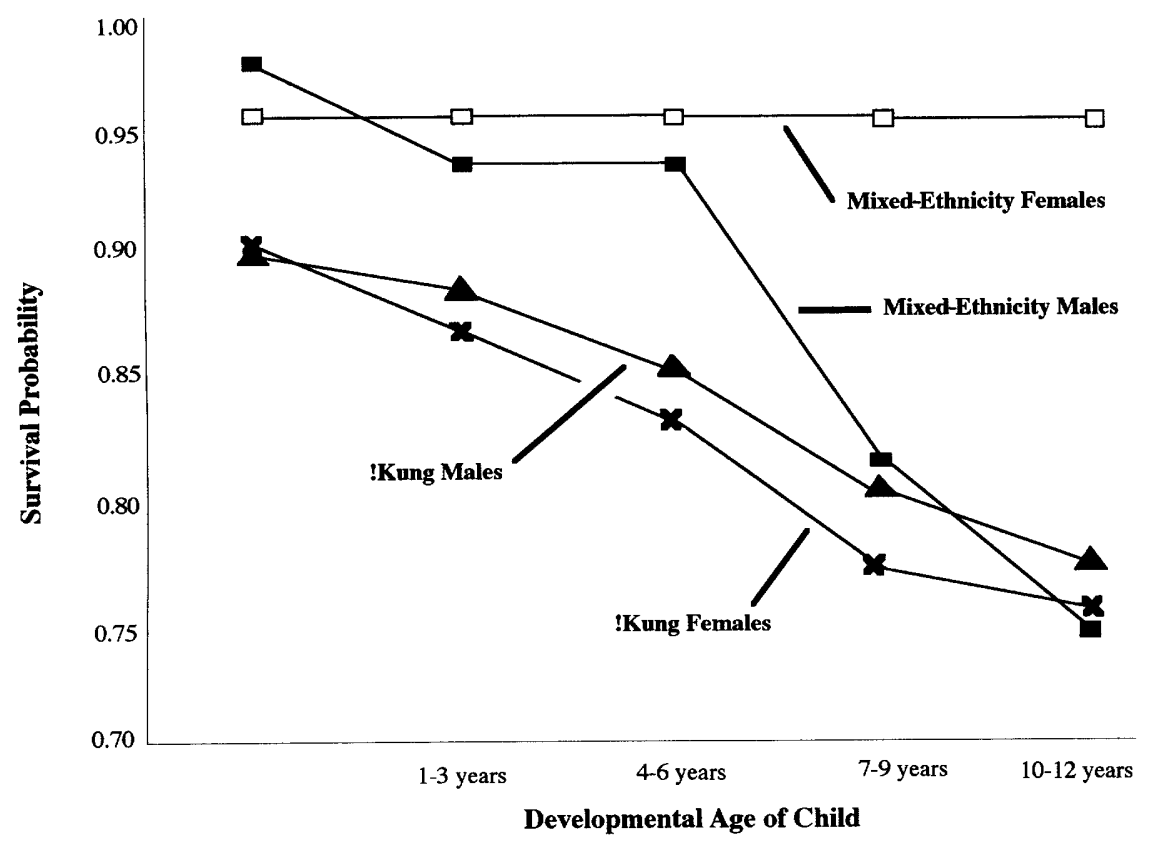

FIGURE 16.2. Survival probabilities for children of interviewed women, by ethnicity and sex. 
higher than that of children both of whose parents are !Kung. These findings, and those discussed below, are based on data on about 700 children born to interviewed parents. At all ages, the children of mixed parentage have a higher probability of surviving than do the full !Kung children (Kranichfeld 1991; Draper and Kranichfeld in progress).

A more interesting picture emerges as shown in figure 16.2 "Survival Probabilities for Children of Interviewed Women, by Ethnicity and Sex." In this display, it is evident that primarily the girls of mixed ethnicity survive at the highest levels, whereas, after about age six, mixed boys lose ground and at age 10-12 years are surviving at lower probabilities than the !Kung males. Given that the modern !Kung are living in a sharply stratified system, and given that they occupy the lowest rung on the ladder, it is tempting to speculate that the sex differences in survivorship, particularly among the children of mixed ethnicity are related to the better marriage or mating possibilities for girls in comparison with boys.

What does all of this mean for any future structuring of gender roles among the !Kung? The "data" presented in this last section are of a different type and pertain to reproductive events, not to everyday economic and social behaviors of men and women. Nevertheless, the demographic data indicate that new developments are taking place and, reproductively speaking, the sexes are not sharing in them equally. !Kung are experiencing profound cultural changes not only in the economic changes but in the increased exposure to non-!Kung ethnic groups whose wealth and levels of education greatly exceed those of the !Kung. Often in considering culture change, one thinks about the impact of new conditions on the recipient group as a whole. In the !Kung case, the entire ethnic group is affected by unilateral changes, yet the responses to those changes are not uniform across the population. Different age cohorts are affected differently as are the two sex groups.

Most !Kung men spoke volubly about the increase in mixed-parentage births. In private conversation, they heaped ridicule and scorn on women who go with Bantu men. They say (as do the mothers of children of mixed ethnicity), "The Bantu do nothing for these children. They just drop them." (But if this is true, why do the children of mixed ethnicity have higher probabilities of surviving to later ages?) One particular man spoke, telling of the male view, and was especially vehement about the liaisons between women of his group and non-!Kung men. He said bitterly, "Besides, where do you see a Bantu woman sleeping with a !Kung man? These women are big and important, and they have possessions. The Bantu women say that a !Kung man is a little thing of no account. They don't notice us."

These demographic developments would not have taken place if other changes were not already in place. Coming in from the bush, of course, exposed !Kung to economic and sexual competition from a wealthier and technologically superior group (Draper and Kranichfeld 1990). As !Kung left the bush, gradually and experimentally, at first, later in larger numbers and with a more permanent commitment to settled life, they found themselves less and less able to exploit the bush for wild foods. The men's hunting role was more severely affected than the women's gathering role, and these effects have accelerated in recent decades. Even by the 1960s, the abundance of game was reduced, according to informants. The majority of !Kung men were not able to compensate quickly enough by replacing their lost value as hunters with acquired value as workers and managers in the new sedentary economy. Meanwhile, what game was left was being disproportionately bagged by Bantu who hunted with firearms and were mounted on the horses and donkeys that the !Kung were not yet able to afford.

Increasing numbers of !Kung women have chosen to mate (not, at present, to marry) with non-!Kung men. This indicates an inability or unwillingness (or both) on the part of the guardians of women to control their reproductive behavior. Does this represent "gains" for women, or does it indicate cultural break- 


\section{Chapter 16}

down? What do the apparent "facts" of the demographic changes I have described have to say about the structuring of gender relations among the !Kung? Are women better off or worse off? In comparison with whom? On the basis of what measures? The question about the future structuring of gender relations among !Kung is not easy to answer. It is evident, however, that it is important to take into account the social structural context of people's lives, the historical epoch in which they live, the ages of specific individuals at the time they experience certain events of cultural change, and the underlying reproductive biol- ogy of the population undergoing the change. In the instance of contemporary !Kung, the reproductive changes leading to changes in family structure have been at least as influential in guiding the future course of !Kung modernization as have been changes in !Kung social structure.

\section{Acknowledgments}

Research was supported by a grant Number AG03110 from the National Institute of Health. Principal Investigators were Christine Fry of Loyola University and Jennie Keith of Swarthmore College. 


\section{The Evolving Female}

A Life-History Perspective

Mary Ellen Morbeck,

Alison Galloway, and

Adrienne L. Ziblman, editors 
Copyright (C) 1997 by Princeton University Press Published by Princeton University Press, 41 William Street, Princeton, New Jersey 08540 In the United Kingdom: Princeton University Press, Chichester, West Sussex

\section{All Rights Reserved}

Library of Congress Cataloging-in-Publication Data

The evolving female : a life-history perspective / edited by Mary Ellen Morbeck, Alison Galloway, and Adrienne L. Zihlman.

p. $\mathrm{cm}$.

Includes bibliographical references and index. ISBN 0-691-02748-X (cloth : alk. paper). ISBN 0-691-02747-1 (pbk. : alk. paper)

1. Human evolution. 2. Women-Evolution.

3. Females-Physiology. 4. Women's studiesBiographical methods.

I. Morbeck, Mary Ellen, 1945- . II. Galloway, Alison, 1953- . III. Zihlman, Adrienne L.

GN281.E93 1996

573.2-dc20 96-20402

This book has been composed in Galliard

Princeton University Press books are printed on acid-free paper and meet the guidelines for permanence and durability of the Committee on Production Guidelines for Book Longevity of the Council on Library Resources

Printed in the United States of America by Princeton Academic Press
$\begin{array}{llllllllll}10 & 9 & 8 & 7 & 6 & 5 & 4 & 3 & 2 & 1\end{array}$
$\begin{array}{llllllllll}10 & 9 & 8 & 7 & 6 & 5 & 4 & 3 & 2 & 1\end{array}$ 